\title{
Knowledge and associated factors of condom use among MSM; a cross sectional study in Global Fund peer led interventions in Sri Lanka
}

\author{
M. Suchira Suranga, D. A. Karawita N. Mudalige, A. Bandara
}

\begin{abstract}
Introduction: Sri Lanka has a lower prevalence of HIV among MSM (0.9\%) in the region. However, the HIV prevalence among MSM has been rising steadily $0.48 \%$ in 2009 and $0.9 \%$ in 2011 . Prevention of HIV transmission through the introduction of "Prevention package" under GFATM round 09 HIV project is one of the main strategies to reduce new infections in the MSM community. Prevention package includes condom awareness and knowledge, condom demonstration and distribution. This project reaches 3203 MSM with the prevention package. Therefore, this study aims to assess the condom knowledge of MSM reached by the peer educators and the factors associated with level of knowledge.
\end{abstract}

Methodology: Multistage probability sampling technique was used to select a sample of 325 MSM peers who have reached with basic HIV prevention service package were interviewed with a structured and semi structured interview schedule after receiving the oral informed-consent. Descriptive statistical analysis and non-parametric hypothesis testing were performed using the SPSS statistical software.

Results: Sample has an average of $4.2(\mathrm{SD}=8.42)$ partner changes per month. One third of the sample had over 10 years of MSM behaviours. Around $70 \%$ of respondents knew at least five out of eight condom use steps. Partner exchange rate, composite knowledge on HIV and using a condom during the last sex were associated with respondents' knowledge on correct use of condoms.

Conclusions: Although the program has contributed significantly to increase the condom use among MSM population, effectiveness of the condom use is questionable. A comprehensive condom demonstration programme must be incorporated into the HIV prevention programs in more practical manner for effective condom programing.

Key words: correct use of condoms, Men who have sex with Men (MSM), HIV, Sri Lanka

\footnotetext{
Authors: corresponding author: Suchira Suranga, M.Phil (Reading), M.Sc., B.Sc (sp) Hons, Deputy Director, Monitoring and Evaluation, The Family Planning Association of Sri Lanka, Email: suchirasuranga@gmail.com, suranga@fpasrilanka.org

Dr Ajith Karawita, MBBS, PgD Ven, MD; Consultant Venereologist, Teaching Hospital, Anuradhapura Nissanka Mudalige, MA, The Family Planning Association of Sri Lanka

Amal Bandara, B.Sc., M.Sc (Reading) The Family Planning Association of Sri Lanka

Acknowledgement: Heart to heart Lanka, Colombo, Saviya Development Foundation, Galle, Sri Lanka Red Cross Society, Kandy branch, Jayadarie Ranathunga, Consultant Venereologist, Duminda Rajakaruna - Specialist in social science,

Kalhara Senadhira - M\&E specialist, Sanjewa Chandrasekara-MIS Officer

Conflict of interest: No conflict of interest

Funding: Global Fund Round 09 HIV prevention Program

Originality, previous publications or presentations: No previous submissions

Submitted: 06.12.2015, Accepted: 17.12.2015
} 


\section{Full Article}

\section{Introduction}

Globally, HIV pandemic remains one of the most serious infectious disease challenges to public health. The HIV prevalence in Sri Lanka is less than $0.1 \%$ according to the National STD/AIDS Control programme (8). Hence, Sri Lanka has been classified by UNAIDS as a country with a low-level HIV epidemic. HIV prevalence among high risk groups like Men who have Sex with Men (MSM), Female Sex Workers (FSWs), Drug Users (DUs), and Beach Boys (BBs) has not reached $5 \%$ and the general population prevalence is less than $0.1 \%$.

The definition used in this survey for MSM is "Men who have had sex with another men in the past six months as a matter of preference or practice, regardless of their sexual identity or sexual orientation, and irrespective of whether they also have sex with women or not".

MSM are disproportionately affected in Sri Lanka by HIV and other sexually transmitted infections including gonorrhoea, syphilis, chlamydia and hepatitis B and C. In several countries in the region, the incidence of these infections has increased among MSM, in some cases markedly, over the last decade. In the recent scattered epidemiological research has identified high HIV prevalence among MSM with varying degrees of study findings and conclusions across countries, India (4.4\%), Thailand (7.1\%), China (6.7\%), Indonesia (8.5\%) and Myanmar (8.9\%) (2). In comparison, Sri Lanka has a lower prevalence of HIV among MSM (0.9\%) in the region (3) . However, MSM population was included as a surveillance group beginning in the 2008 HIV Sentinel Sero-Surveillance Survey (HSS) and HIV prevalence among this group has been rising steadily at close to $0 \%$ in $2008,0.48 \%$ in 2009 and $0.9 \%$ in 2011 (4). Overall, 11\% of the total reported HIV infections are attributable to homosexual transmission in Sri Lanka (4). The current estimation of MSM in Sri Lanka is
7,551 (ranging from 6,547 to 8,554 ) across 1,438 hot spots (5).

Unprotected anal intercourse (UAI) is the main cause of HIV transmission between gay and bisexual men or MSM. The higher incidence of HIV observed among MSM as compared with heterosexual populations in similar settings is largely due to the higher transmissibility of HIV via anal intercourse (3). Prevention of HIV transmission through correct and consistence use of condoms is the most effective and important prevention strategy for MSM which demands more focus behavioral change interventions (6). However, recent Integrated Biological Behavioral Surveillance survey (IBBS) highlight that, Global AIDS Response Progress Reporting (GARPR) indicators around the biological component are low (aggregate HIV prevalence: $<1.0 \%$, and aggregate syphilis prevalence $<2.0 \%$ ) but the behavioral indicators are not performing well with the emphasis on low HIV testing, lack of comprehensive knowledge on HIV and relatively low level of condom use. Just over half $(57.9 \%)$ of MSM has reported using a condom during the last anal sex with another man (3). This evident that condom usage among this population is moderate but correct use of condoms is further explorative. This study addresses the knowledge gaps of correct use of condoms.

GFATM round 09 Project (2012-2015) is implemented in Sri Lanka for prevention of HIV amongst most at risk populations (MARP) as a part of national HIV prevention program. The project reached 3203 MSM with a basic HIV prevention package through MSM peer educators (PE) by end of 2014. The peer educators are selected from the same community and provided a five-day training workshop which comprehensively encompasses on HIV, Sexually Transmitted Infections (STI), Communication, Peer Education and basic aspects of monitoring and evaluation. The Peer Educators are expected to provide basic package of HIV prevention services to their peers. The basic 
package of HIV prevention services includes creating awareness on HIV and STI, Condom demonstration and distributions, creating awareness through distribution of IEC materials and escorting peers to government STI clinics for additional services such as HIV testing and counselling, treatment for STI (7) . The condom program of the project mainly focuses on comprehensive demonstration and distribution; an average distribution of 15 condoms per MSM per month. Condom demonstration is elaborated as "A trained peer educator meets one or more of his peers registered in the project, and provides information on importance of condom use and demonstrate following steps of correct use of male condoms.

1. Inspect the condom and expiry date.

2. Tear the condom free edge of package and take out the condom. Ensure that the nails do not cause a tear in the condom.

3. To prevent the condom from bursting, squeeze the tip of the condom to take out the air.

4. While holding onto the tip, unroll the condom down the shaft of the penis all the way to the base of penis.

5. After the sex, slide off the condom from the penis ensuring that the semen collected at the tip does not spill or leak out.

6. Dispose-off the condom in a safe place where it cannot be handled by another person.

7. Wash hands, if semen or vaginal secretions contact on the hand.

8. Use a tissue or a paper to remove the condom to prevent potential contact of vaginal secretions in the hand. It is important but not mandatory to use a dildo to conduct a condom demonstration (8).

The objective of the study was to assess the knowledge of MSM reached by the program (peers) on correct use of condoms for prevention of HIV and associated factors.
Methods

Three hundred and twenty-five (325) MSM peers who have reached with basic HIV prevention service package were selected using a multi-stage probability sampling method. The sample size was calculated using McCallum Layton online sample size calculator (9). The main peer registration database of the GFATM project was used as the sampling frame. This study consists of two components namely; a formal structured interview schedule and a semi structured indepth interview. First the formal structured interview schedule was administered which consists of demographical characteristics, (age, marital status, level of education, MSM category), composite knowledge on HIV, HIV risk behaviours (number of sexual partners during the last month, duration in MSM behaviour) and safe sex practices (HIV testing, Condom Use). Then a semi structured indepth interview was conducted with probing questions to assess the respondents' awareness on the eight steps on correct use of condoms. The tool was developed by a multi-disciplinary group of expert consisted of Venereologists, Monitoring and Evaluation experts and experts in sociology and anthropology. By adopting existing guideline developed by UNODC for peer led interventions among drug users (10). The tool was pre-tested with 15 MSM with deferent demographic characteristics and revised accordingly before finalizing it.

The respondents were clearly briefed that the information collected will be treated with utmost confidentiality and will be only used for the research purposes, with anonymity. After taking the respondents oral consent the data was collected and recorded. The interviews were conducted by a team of Monitoring and Evaluation professionals who have field level experience in working with MSM at least three years. The selected peers were reached through their peer educators and field supervisors. The interviews were conducted at their hot-spots or places convenient to them. The enumerators were 
conducted re-visits to their hot-spots maximum up to three times, if the selected peer is not available for the interviews at the time of the visit. However, this study was not subjected to an ethical review process, as the field survey was conducted among group of project beneficiaries who are well aware of the project and project activities. Data collected was cleaned and entered in to SPSS statistical software. Descriptive statistical analysis and non-parametric hypothesis tests were performed accordingly.

\section{Results}

\section{Sample Characteristics}

Two hundred and eighty-one valid responses were received resulting 86 percent response rate. Response rate is somewhat lower than the standard for social surveys due to nature of the target population and difficulties in accessibility. The non-response rate was three times higher in urban areas of Colombo district in comparison to other locations. More than 50 percent of the respondents were recruited from Colombo and Galle districts align with the population coverage of the program. Around one third of the respondents represent rural communities of five selected districts. In the absence of clear demarcation of transgender communities in Sri Lanka, the self-identified "Nachchi" respondents can be considered as a proxy. Around 12 percent of respondents were selfidentified them as "Nachchi" which is somewhat lower than the figure reported in Colombo (28 percent), and Anuradhapura (26 percent) districts and higher than Galle (9 percent) in the IBBS survey (3).

Table 1: Sample distribution by district, location and category of MSM

\begin{tabular}{llll}
\hline \multicolumn{2}{l}{ Characteristics } & Freq & Percent \\
\hline \multirow{5}{*}{ District } & Anuradhapura & 35 & $12.5 \%$ \\
\cline { 2 - 4 } & Colombo & 81 & $28.8 \%$ \\
\cline { 2 - 4 } & Galle & 73 & $25.9 \%$ \\
\cline { 2 - 4 } & Gampaha & 53 & $18.9 \%$ \\
\cline { 2 - 4 } & Kalutara & 39 & $13.9 \%$ \\
\cline { 2 - 4 } & Subtotal & $\mathbf{2 8 1}$ & $\mathbf{1 0 0 . 0 \%}$ \\
\hline \multirow{2}{*}{ Location } & Urban & 118 & $41.9 \%$ \\
\cline { 2 - 4 } & Peri Urban & 77 & $27.4 \%$ \\
\hline
\end{tabular}

\begin{tabular}{|llll}
\hline \multirow{5}{*}{ Category } & Rural & 86 & $30.6 \%$ \\
\cline { 2 - 4 } & Subtotal & $\mathbf{2 8 1}$ & $\mathbf{1 0 0 . 0 \%}$ \\
\cline { 2 - 4 } & MSM & 187 & $81.7 \%$ \\
\cline { 2 - 4 } & Nachchi & 28 & $12.2 \%$ \\
\cline { 2 - 4 } & MSW & 3 & $1.3 \%$ \\
\cline { 2 - 4 } & MSM Other & 11 & $4.8 \%$ \\
\cline { 2 - 4 } & Subtotal & $\mathbf{2 2 9}$ & $\mathbf{1 0 0 . 0 \%}$ \\
\hline
\end{tabular}

\section{Distribution of Socio-demographic} characteristics and HIV risk behaviours

The socio-demographic characteristics shows (Table 2) that the mean age of the respondents was 28 years $(S D=9.17)$ ranging from 18 to 81 years. Over half of them (56\%) are youth (less than 25 years). Around 70 percent of the respondents were never married and another 5 percent of respondents are living together with another man. The mean number of years of formal education was reported as 11 years $(S D=2.94)$ ranging from no formal education to 21 years of formal education.

An average partner exchange rate was 4.2 males per month $(S D=8.42)$ One third of respondents have been MSM for more than 10 years.

Table 2: Sample characteristics

\begin{tabular}{|c|c|c|c|}
\hline & & Frequency & Percentage \\
\hline \multirow{5}{*}{$\begin{array}{l}\text { Age (No of } \\
\text { years } \\
\text { completed) }\end{array}$} & Less than 25 & 156 & $55.5 \%$ \\
\hline & 26 to 35 & 72 & $25.6 \%$ \\
\hline & 36 to 50 & 43 & $15.3 \%$ \\
\hline & Above 50 & 10 & $3.6 \%$ \\
\hline & Subtotal & 281 & $100.0 \%$ \\
\hline \multirow{6}{*}{$\begin{array}{l}\text { Marital } \\
\text { Status }\end{array}$} & Never Married & 194 & $70.6 \%$ \\
\hline & Married & 55 & $20.0 \%$ \\
\hline & $\begin{array}{l}\text { Living together (with } \\
\text { a male) }\end{array}$ & 14 & $5.1 \%$ \\
\hline & Divorced & 6 & $2.2 \%$ \\
\hline & Widow & 6 & $2.2 \%$ \\
\hline & Subtotal & 275 & $100.0 \%$ \\
\hline \multirow{5}{*}{$\begin{array}{l}\text { Formal } \\
\text { Education }\end{array}$} & Year 05 or less & 14 & $5.3 \%$ \\
\hline & Year 05 to GCE O/L & 148 & $56.3 \%$ \\
\hline & GCE A/L & 89 & $33.9 \%$ \\
\hline & Above GCE A/L & 12 & $4.6 \%$ \\
\hline & Subtotal & 263 & $100.0 \%$ \\
\hline \multirow{6}{*}{$\begin{array}{l}\text { Duration of } \\
\text { MSM } \\
\text { behaviour }\end{array}$} & Less than 01 Year & 16 & $6.1 \%$ \\
\hline & 1 to 5 years & 98 & $37.3 \%$ \\
\hline & 6 to 10 years & 62 & $23.6 \%$ \\
\hline & 11 to 20 years & 71 & $27.0 \%$ \\
\hline & More than 20 years & 16 & $6.1 \%$ \\
\hline & Subtotal & 263 & $100.0 \%$ \\
\hline \multirow{7}{*}{$\begin{array}{l}\text { No of male } \\
\text { sexual } \\
\text { partners } \\
\text { during the } \\
\text { last month }\end{array}$} & None & 66 & $9.7 \%$ \\
\hline & 1 to 3 & 136 & $57.1 \%$ \\
\hline & 4 to 5 & 41 & $17.2 \%$ \\
\hline & 5 to 10 & 21 & $8.8 \%$ \\
\hline & 11 to 30 & 13 & $5.46 \%$ \\
\hline & Above 30 & 4 & $1.6 \%$ \\
\hline & Subtotal & 281 & $100.0 \%$ \\
\hline
\end{tabular}




\section{Knowledge on condom use steps}

In the event of 90 percent of respondents reported using condoms during the last anal sex, it is important to explore whether the use has been correct. Hence, as explained in the methodology, this study gathered information on respondents' awareness on the eight condom use steps (table 3 )

Table 3: Knowledge on condom use steps

\begin{tabular}{|c|c|c|c|}
\hline & \multirow[t]{2}{*}{ Correct condom use steps } & \multicolumn{2}{|c|}{$\begin{array}{l}\text { Steps followed? } \\
\qquad(N=281)\end{array}$} \\
\hline & & Yes (\%) & No (\%) \\
\hline 1 & $\begin{array}{l}\text { Inspection of the condom } \\
\text { and expiry date. }\end{array}$ & $167(59.4)$ & $114(40.6)$ \\
\hline 2 & $\begin{array}{l}\text { Correct tearing \& removal } \\
\text { without damage }\end{array}$ & $225(80.1)$ & 56 (19.9) \\
\hline 3 & Squeeze the condom tip & $216(76.9)$ & $65(23.1)$ \\
\hline 4 & Unrolling technique & $241(85.8)$ & $40(14.2)$ \\
\hline 5 & $\begin{array}{l}\text { Removing and Sliding off the } \\
\text { condom }\end{array}$ & $227(80.8)$ & $54(19.2)$ \\
\hline 6 & Condom disposal method & $170(60.5)$ & $111(39.5)$ \\
\hline 7 & $\begin{array}{l}\text { Wash hands, if semen or } \\
\text { secretions contact on hand }\end{array}$ & $190(67.6)$ & $91(32.4)$ \\
\hline 8 & $\begin{array}{l}\text { Use a tissue or a paper to } \\
\text { remove the condom }\end{array}$ & $146(51.9)$ & $135(48.0)$ \\
\hline
\end{tabular}

\section{Factors associated with knowledge on condom use steps}

A scale of 1 to 8 was developed by taking number of steps correctly mentioned by each respondents. The lower scores represent weak knowledge on condom use steps and higher scores represent comprehensive knowledge. The scale shows an acceptable level of internal validity with 0.759 Cronbach's alpha (11).

We found that the number of sexual partners during the last month is positively associated with respondents' level of knowledge on condom wearing steps and safe practices (spearman $r=0.169, p=0.009$ ). More specifically, the respondents who have higher number male sexual partners are likely to compose a better knowledge on condom wearing steps. This can be partially attributed to the effect of current and previous HIV programs which focuses on most at risk populations.

As anticipated, respondents' composite knowledge on HIV prevention is also positively associated with the knowledge on condom wearing steps and safe practices $(r=0.275$, $p=0.000$ ). Similarly, those who are using condoms are likely to have better knowledge on condom wearing steps than non-users (Chi2 $=12.422, \mathrm{P}=0.012)$. Respondents' age, years of formal education, marital status and number of years in MSM behavior are not significantly associated with knowledge on condom wearing steps and safe practices. Table 4 further demonstrate the factors associated with knowledge on condom wearing steps and safe practices. 
Table 4: Factors associated with knowledge on condom wearing steps and safe practices

\begin{tabular}{|c|c|c|c|c|c|c|c|c|}
\hline & & \multicolumn{2}{|l|}{ Frequencies } & \multicolumn{2}{|c|}{$\begin{array}{l}\text { Total SCORE } \\
\text { Condom }\end{array}$} & \multicolumn{3}{|c|}{ Awareness on Correct use of } \\
\hline & & $\begin{array}{r}\text { \# of } \\
\text { respondents }\end{array}$ & $\begin{array}{r}\% \text { of } \\
\text { respondents }\end{array}$ & Mean & Median & $\begin{array}{r}\text { Mean } \\
\text { Rank }\end{array}$ & $\begin{array}{l}\text { Spearman } \\
\text { Rank } \\
\text { Correlation }\end{array}$ & $\begin{array}{l}\text { Kruskal - } \\
\text { Wallies } \\
\text { Test }\end{array}$ \\
\hline \multirow{3}{*}{$\begin{array}{l}\text { Age (No of } \\
\text { years) }\end{array}$} & Less than 25 & 156 & $55.5 \%$ & 5.2 & 6.0 & 139.2 & \multirow{3}{*}{$\begin{array}{c}r=-0.015 \\
p=0.800\end{array}$} & \multirow[t]{3}{*}{$N / A$} \\
\hline & Above 25 & 125 & $44.5 \%$ & 5.4 & 6.0 & 143.3 & & \\
\hline & Subtotal & 281 & $100.0 \%$ & 5.3 & 6.0 & & & \\
\hline \multirow{3}{*}{$\begin{array}{l}\text { Education } \\
\text { (No of } \\
\text { years) }\end{array}$} & Up to year 10 & 78 & $29.7 \%$ & 5.3 & 6.0 & & \multirow{3}{*}{$\begin{array}{l}r=0.045 \\
p=0.464\end{array}$} & \multirow[t]{3}{*}{$N / A$} \\
\hline & O/L and above & 185 & $70.3 \%$ & 5.4 & 6.0 & & & \\
\hline & Subtotal & 263 & $100.00 \%$ & 5.4 & 6.0 & & & \\
\hline \multirow{6}{*}{$\begin{array}{l}\text { Marital } \\
\text { Status }\end{array}$} & Never Married & 194 & $70.6 \%$ & 5.3 & 5.0 & 137.9 & \multirow[t]{6}{*}{$N / A$} & \multirow{6}{*}{$\begin{array}{c}\text { Chi2 = } \\
2.440 \\
p=0.655\end{array}$} \\
\hline & Married & 55 & $20.0 \%$ & 5.0 & 6.0 & 129.3 & & \\
\hline & Living together & 14 & $5.1 \%$ & 5.9 & 6.0 & 157.4 & & \\
\hline & Divorced & 6 & $2.2 \%$ & 5.7 & 6.0 & 146.9 & & \\
\hline & Widow & 6 & $2.2 \%$ & 6.2 & 6.5 & 167.4 & & \\
\hline & Subtotal & 275 & $100.0 \%$ & 5.3 & 6.0 & & & \\
\hline \multirow{7}{*}{$\begin{array}{l}\text { No of } \\
\text { Sexual } \\
\text { Partners } \\
\text { During the } \\
\text { last month }\end{array}$} & None & 23 & $9.7 \%$ & 5.3 & 6.0 & 117.5 & \multirow{7}{*}{$\begin{array}{c}r=0.169 * * \\
p=0.009\end{array}$} & \multirow[t]{7}{*}{$N / A$} \\
\hline & 1 to 3 & 136 & $57.1 \%$ & 4.9 & 5.0 & 109.5 & & \\
\hline & 4 to 5 & 41 & $17.2 \%$ & 5.8 & 6.0 & 135.9 & & \\
\hline & 5 to 10 & 21 & $8.8 \%$ & 5.9 & 6.0 & 134.5 & & \\
\hline & 11 to 30 & 13 & $5.5 \%$ & 6.2 & 7.0 & 149.7 & & \\
\hline & Above 30 & 4 & $1.7 \%$ & 5.8 & 5.5 & 126.4 & & \\
\hline & Subtotal & 238 & $100.0 \%$ & 5.3 & 6.0 & & & \\
\hline \multirow{6}{*}{$\begin{array}{l}\text { No of Years } \\
\text { in MSM } \\
\text { behavior }\end{array}$} & Less than 01 Year & 16 & $6.1 \%$ & 3.3 & 3.5 & 74.2 & \multirow{6}{*}{$\begin{array}{l}r=0.094 \\
p=0.129\end{array}$} & \multirow[t]{6}{*}{$N / A$} \\
\hline & 1 to 5 years & 98 & $37.3 \%$ & 5.5 & 6.0 & 138.3 & & \\
\hline & 6 to 10 years & 62 & $23.6 \%$ & 5.3 & 6.0 & 127.9 & & \\
\hline & 11 to 20 years & 71 & $27.0 \%$ & 5.6 & 6.0 & 140.4 & & \\
\hline & More than 20 years & 16 & $6.1 \%$ & 5.4 & 5.5 & 129.9 & & \\
\hline & Subtotal & 263 & $100.0 \%$ & 5.4 & 6.00 & & & \\
\hline \multirow[t]{4}{*}{ Location } & Urban & 118 & $41.9 \%$ & 5.2 & 5.00 & 137.4 & \multirow[t]{4}{*}{$N / A$} & \multirow{4}{*}{$\begin{array}{c}\text { Chi2 } \\
=3.568 \\
p=0.168\end{array}$} \\
\hline & Peri Urban & 77 & $27.4 \%$ & 4.9 & 5.00 & 131.8 & & \\
\hline & Rural & 86 & $30.6 \%$ & 5.6 & 6.00 & 154.2 & & \\
\hline & Subtotal & 281 & $100.0 \%$ & 5.3 & 6.0 & & & \\
\hline \multirow{3}{*}{$\begin{array}{l}\text { Used a } \\
\text { Condom } \\
\text { During the } \\
\text { last Sex }\end{array}$} & No & 27 & $9.8 \%$ & 4.6 & 5.0 & 115.7 & \multirow[t]{3}{*}{$N / A$} & \multirow{3}{*}{$\begin{array}{c}\text { Chi2 = } \\
12.422 \\
p=0.012^{*}\end{array}$} \\
\hline & Yes & 248 & $90.2 \%$ & 5.4 & 6.0 & 140.4 & & \\
\hline & Subtotal & 275 & $100.0 \%$ & 5.3 & 6.0 & & & \\
\hline \multirow{4}{*}{$\begin{array}{l}\text { Composite } \\
\text { Knowledge } \\
\text { on HIV } \\
\text { (Total } \\
\text { Knowledge } \\
\text { Score) }\end{array}$} & Poor (Score 1-3) & 28 & $9.9 \%$ & 4.3 & 4.5 & 103.7 & \multirow{4}{*}{$\begin{array}{l}r=0.275^{* *} \\
p=0.000\end{array}$} & $N / A$ \\
\hline & Average (Score 4-5) & 136 & $48.4 \%$ & 4.9 & 5.0 & 127.5 & & \\
\hline & Good (Score 6-7) & 117 & $41.6 \%$ & 5.9 & 6.0 & 165.7 & & \\
\hline & Subtotal & 281 & $100.0 \%$ & 5.3 & 6.0 & & & \\
\hline
\end{tabular}

Discussion

The project reached about 42 percent of estimated number of MSM in Sri Lanka (5).
Around 90 percent of responded reported a use of condoms during the last anal sex which is remarkably higher than the population estimates reported in recent IBBS (Colombo- 
64\%, Galle-37\% and Anuradhapura 55\%) (3). However, only around $70 \%$ of respondents knew at least five out of eight condom use steps. Although the program has contributed significantly to increase the condom use among MSM population, effectiveness of the condom use is questionable.

Hence, these findings highlight that HIV education and distribution of condom among most at risk populations alone do not enough to handle the issue. A comprehensive condom demonstration programme must be incorporated in to the HIV prevention programs in more practical manner for effective condom programing. Currently, Sri Lanka does not have standard tools and guidelines for condom demonstrations and to measure effectiveness of knowledge transfer. Development and pilot testing of tools and national guidelines on condom demonstration and measuring effective use of condoms are priority areas for further development of condom programing in Sri Lanka. Further, the outreach workers must be trained adequately to conduct comprehensive condom demonstration programs giving equal importance and adequate time to discuss all the steps to promote correct use of condoms.

\section{Conclusion}

Although the program has contributed significantly to increase the condom use among MSM population up to 90 percent, effectiveness of the condom use is questionable. A comprehensive condom demonstration programme must be incorporated in to the HIV prevention programs in more practical manner for effective condom programing. Further, HIV prevention program should closely monitor effective use of condoms apart from condom distribution.

\section{References}

1. National STD/AIDS Control Programme. Annual Report 2014/15 Colombo: National STD/AIDS Control Programme, Ministry of Health; 2015.

2. Joint United Nations Program on HIV AIDS. HIV in Asia and the pacific: Joint United Nations Program on HIV AIDS; 2007.

3. National STD/AIDS Control Program. Integrated Biological and Behavioural Surveillance (IBBS) Survey among Key Populations at Higher Risk of HIV in Sri Lanka. Colombo: Ministry of Health, National STD/AIDS Control Programme; 2014.

4. Rawstorne P, Worth H. Sri Lanka Behavioural Surveilance Survey Results - 2006. 1st ed. Colombo: Ministry of Health Care and Nutrition; 2007.

5. National STD/AIDS Control Programme. National size estimation of most-at-risk populations (MARPs) for HIV in Sri Lanka. Colombo: Ministry of Health, National STD/AIDS Control Programme; 2013.

6. National STD/AIDS Control Program. National HIV Strategic Plan 2013-2017 - Sri Lanka Colombo: National STD/AIDS Control Programme; 2013.

7. GFATM Country Cordination Mechanism (CCM) - Sri Lanka. Project Proporsal - Global Fund Round 09 Project. Colombo - Sri Lanka:; 2009.

8. The Family Planning Association of Sri Lanka. Procedure Manual for Implementation of GFATM round 09 HIV prevention program. 1st ed. Colombo: The Family Planning Association of Sri Lanka; 2014.

9. McCallum Layton. McCallum Layton. [Online].; 2015 [cited 2014 November 10. Available from: https://www.mccallum-layton.co.uk/tools/statisticcalculators.

10. Sethi HS, Suruchi P. Bringing the gap between service providers and drug users in peer led interventions; Training of Trainer Manual for trainers, outreach and field workers.: United Nations Office on Drug and Crime (UNODC) - Regional Office for South Asia; 2005.

11. Tavakol M, Dennick R. Making sense of Cronbach's alpha. International Journal of Medical Education. 2011; 2: p. 53-55. 